\title{
Magnetically recoverable carbon-coated iron carbide with arsenic adsorptive removal properties
}

\author{
Camilah D. Powell ${ }^{1,2} \cdot$ Sujin Guo ${ }^{2,3} \cdot$ Lea M. Godret-Miertschin ${ }^{1,2} \cdot$ Karen Ventura 2,6 . Amanda W. Lounsbury ${ }^{2,7}$. \\ Chelsea A. Clark ${ }^{1,2}$. Dino Villagran ${ }^{2,6}$. Julie B. Zimmerman ${ }^{2,7}$. Ariel J. Atkinson ${ }^{2,8}$ • Paul Westerhoff ${ }^{2,8}$. \\ Michael S. Wong ${ }^{1,2,3,4,5}$
}

Received: 8 May 2020 / Accepted: 3 September 2020 / Published online: 12 September 2020

(c) Springer Nature Switzerland AG 2020

\begin{abstract}
Magnetic particles, generally nanostructured and magnetite-based, have been studied extensively to remove drinking water contaminants. Compositions beyond $\mathrm{Fe}_{3} \mathrm{O}_{4}$ could address long-standing issues of magnetic recoverability and materials integrity in drinking waters. Herein carbon-coated iron carbide $\left(\mathrm{Fe}_{3} \mathrm{C} @ \mathrm{C}\right)$ were studied for the first time for their stability, magnetic characteristics, magnetic separability, and arsenic adsorptive properties. Experimental results show that (i) $\mathrm{Fe}_{3} \mathrm{C} @ \mathrm{C}$ with a 9-nm thick graphitic shell is chemically stable in simulated drinking water; (ii) is ferromagnetic with small magnetic remanence and a magnetic saturation that is $\sim 2 \times$ greater than $\mathrm{Fe}_{3} \mathrm{O}_{4}$; (iii) can be separated from water magnetically under continuous-flow conditions with greater than $99 \%$ recovery; and (iv) has a surface area-normalized adsorption capacity for arsenic $\left(6.75 \mu \mathrm{g} / \mathrm{m}^{2}\right)$ of the same order of magnitude as that of $\mathrm{Fe}_{3} \mathrm{O}_{4}\left(9.62 \mu \mathrm{g} / \mathrm{m}^{2}\right)$. $\mathrm{Fe}_{3} \mathrm{C} @ \mathrm{C}$ can be a viable alternative to $\mathrm{Fe}_{3} \mathrm{O}_{4}$ with further development, for the magnetic removal of arsenic and other contaminants from drinking water sources.
\end{abstract}

Graphic abstract A comparative look at the chemical stability, adsorptive prowess, and magnetic capturability of nanostructured carbon-coated iron carbide for arsenic removal from simulated drinking water.

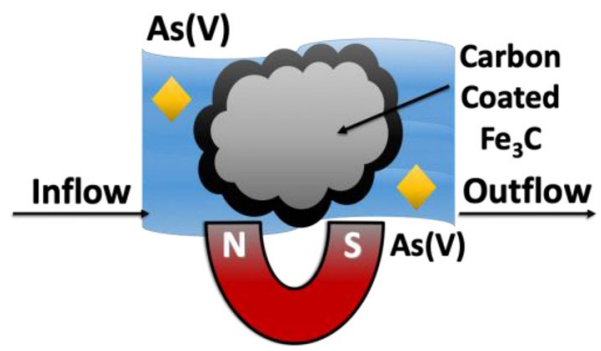

Keywords Environmental nanotechnology $\cdot$ Adsorption $\cdot$ Nano-magnetism $\cdot$ Arsenic

Electronic supplementary material The online version of this article (https://doi.org/10.1007/s42452-020-03491-7) contains supplementary material, which is available to authorized users.

Michael S. Wong, mswong@rice.edu| ${ }^{1}$ Chemical and Biomolecular Engineering, Rice University, Houston, TX, USA. ${ }^{2}$ Nanosystems Engineering Research Center for Nanotechnology-Enabled Water Treatment, Houston, TX, USA. ${ }^{3}$ Civil and Environmental Engineering, Rice University, Houston, TX, USA. ${ }^{4}$ Chemistry, Rice University, Houston, TX, USA. ${ }^{5}$ Material Science and NanoEngineering, Rice University, Houston, TX, USA. ${ }^{6}$ Department of Chemistry and Biochemistry, University of Texas at El Paso, El Paso, TX, USA. ${ }^{7}$ Chemical and Environmental Engineering, Yale University, New Haven, CT, USA. ${ }^{8}$ School of Sustainable Engineering and The Built Environment, Arizona State University, Tempe, AZ, USA. 


\section{Introduction}

Nanocrystalline magnetite is one of the most commonly studied magnetic engineered nanomaterial (ENM) for water treatment [1] due to: (1) its ability to be easily removed from the reaction medium via magnet capture [2], (2) its ability to remove a host of contaminants ranging from heavy metals to organic compounds [2-7], and (3) the relatively low toxicity concern of iron $[1,8]$. Nanocrystalline $\mathrm{Fe}_{3} \mathrm{O}_{4}$ is commercially available, easy to synthesize, and has size dependent magnetic properties such as superparamagnetism which emerges for single crystalline particle sizes $<50 \mathrm{~nm}$, enabling its recovery and reuse. Such advantages have led to pilot-scale testing, for example, layered double hydroxides (LDH)/silica/ magnetite and lanthanum-based magnetite ENMs for phosphorous removal from wastewater streams $[9,10]$ and uncoated magnetite ENMs for treating arsenic contaminated ground water wells in Mexico [11]. Even more so, literature is replete with studies that catalog the use of iron-based nanoparticles for the removal or organic contaminants, heavy metals (i.e., $\mathrm{Zn}(\mathrm{II}), \mathrm{Cu}(\mathrm{II}), \mathrm{Pb}(\mathrm{II})$, $\mathrm{Cr}(\mathrm{III}))$, and anions (i.e., nitrates, arsenates, etc.) [12, 13]. However, there are still barriers (i.e., selectivity, regeneration, capturability, and stability) that prevent magnetic ENM treatment from being implemented in large-scale water treatment applications $[9,14]$. Most studies surrounding magnetic ENMs for wastewater applications do not address leaching and lower performance issues that could occur when testing in drinking waters $[1,8,15,16]$.

A major hurdle to using iron oxides in drinking water treatment schemes is that iron-based nanoparticles have limited chemical stability in water [7, 17]. Specifically, for $\mathrm{Fe}_{3} \mathrm{O}_{4}$, the surface $\mathrm{Fe}^{2+}$ sites of $\mathrm{Fe}_{3} \mathrm{O}_{4}$ slowly oxidize, which lowers their magnetic saturation $[3,18]$. Under acidic conditions, the $\mathrm{Fe}^{3+}$ readily leaches into solution [19-22]. To combat these issues, protective coatings are used to increase material stability, but the resulting core-shell structure has lower magnetic strength [23]. A greater magnetic field strength or gradient would be needed for complete recovery, as the attractive magnetic force is dependent in part on the material's magnetization [24-28].

It is notable that most reported nanocrystalline $\mathrm{Fe}_{3} \mathrm{O}_{4}$-based absorbents have non-zero magnetic remanence and coercivity values, and are therefore not technically superparamagnetic [29-31]. However, their magnetic remanence and coercivity values are sufficiently small to allow for aggregation/disaggregation in the presence/ absence of a magnetic field. Such materials may be suitable for water treatment scenarios in which partially magnetized particle aggregates can be tolerated.
Alternative iron compositions could improve the magnetic recovery and stability issues of iron oxide-based magnetic ENMs in water treatment. One such material is carbon-coated iron carbide (" $\left.\mathrm{Fe}_{3} \mathrm{C} @ \mathrm{C} "\right)$. Containing $6.7 \mathrm{wt} \%$ carbon and $93.3 \mathrm{wt} \%$ iron [32], $\mathrm{Fe}_{3} \mathrm{C}$ has been studied as a nonprecious metal catalyst for oxygen reduction reactions in neutral and alkaline solutions; it dissolves under acidic conditions though [33,34]. $\mathrm{Fe}_{3} \mathrm{C}$ has a higher magnetic strength than bulk $\mathrm{Fe}_{3} \mathrm{O}_{4}$ (e.g., $140 \mathrm{emu} / \mathrm{g}$ [35] vs. $92 \mathrm{emu} / \mathrm{g}$ [30]) and retains its magnetic strength when crystal domain sizes are reduced to the nanoscale [11, 33, $34,36]$. Synthesized through gas-phase pyrolysis or flame spray techniques, nano-sized $\mathrm{Fe}_{3} \mathrm{C} @ \mathrm{C}$ carries a graphitic coating that protects the $\mathrm{Fe}_{3} \mathrm{C}$ surface from oxidizing. $\mathrm{Fe}_{3} \mathrm{C} @ \mathrm{C}$ has magnetic remanence and coercivity values somewhat similar with those of "superparamagnetic" $\mathrm{Fe}_{3} \mathrm{O}_{4}$ nanoparticles found in literature $[29,31]$. A variety of magnetic carbon-based absorbents such as graphene oxide nickel ferrite, multiwalled carbon nanotubes/ironoxide composites, magnetic biochar, and carbon encapsulated maghemite/magnetite, etc., are used for arsenic and heavy metal adsorption due to their facile magnetic recovery and the adsorptive prowess of carbon [13, 37-49]. However, none - to the authors knowledge—have studied $\mathrm{Fe}_{3} \mathrm{C} @ \mathrm{C}$ for arsenic removal in simulated drinking water.

There are no studies that assess the arsenic removal properties of $\mathrm{Fe}_{3} \mathrm{C} @ \mathrm{C}$. Arsenic removal from drinking water sources remains to be an issue of concern $[15,16$, $50,51]$. Large rural populations around the world that use private wells as their main source of drinking water, continue to be exposed to arsenic levels above the WHO provisional guideline for arsenic (i.e., $10 \mu \mathrm{g} / \mathrm{L}$ ) with arsenic levels ranging between $10-50 \mu \mathrm{g} / \mathrm{L}[52,53]$. In this work, we evaluate the arsenic adsorptive properties and chemical stability of Fe3C@C in deionized water and simulated drinking water along with its magnetic recovery under flowing conditions. We subjected a commercially sourced $\mathrm{Fe}_{3} \mathrm{C} @ \mathrm{C}$ to stability batch tests under mild and aggressive conditions (i.e., $60^{\circ} \mathrm{C}$ and $\mathrm{pH} 3$ ), monitoring for dissolved iron. We quantified its adsorption isotherms for arsenic and studied its magnetic separation from water using an in-house permanent-magnet capture device. We used four common iron-based nanopowders (nanocrystalline materials in powdered form) for comparison: commercially available $\mathrm{Fe}_{3} \mathrm{O}_{4}$, commercially available $\mathrm{Fe}_{3} \mathrm{O}_{4}$ with a $\mathrm{SiO}_{2}$ coating, as-synthesized $\mathrm{Fe}_{3} \mathrm{O}_{4}$, and as-synthesized $\mathrm{a}-\mathrm{Fe}_{2} \mathrm{O}_{3}$ nanopowder. Our analyses show that $\mathrm{Fe}_{3} \mathrm{C} @ \mathrm{C}$ (i) is chemically and magnetically stable in simulated drinking water; (ii) has surface-area-normalized adsorption capacity for arsenic comparable to commercially used iron oxide hydroxide adsorbent Bayoxide E33; and (iii) can be effectively removed from flowing water using a permanent magnet. 


\section{Materials and methods}

\subsection{Materials}

All iron-based materials studied were nanopowders, i.e., in powdered form and containing XRD-detectible nanocrystalline domains. Carbon coated iron carbide nanopowder ("Fe ${ }_{3} \mathrm{C} @ \mathrm{C} " ;$ prepared through a high-temperature plasma chemical vapor deposition process) from Nanostructured \& Amorphous Materials Inc. and commercial $\mathrm{Fe}_{3} \mathrm{O}_{4}$ nanopowder ("c- $\mathrm{Fe}_{3} \mathrm{O}_{4}$ ") from Sigma Aldrich were used for the stability, magnetic recovery, and adsorption experiments (Table S1). As-received iron oxide hydroxide goethite granules (Bayoxide E33; CAS \#51274-00-1; from Lanxess) were crushed and used for the adsorption studies. The silica coating for "c- $\mathrm{Fe}_{3} \mathrm{O}_{4} @$ $\mathrm{SiO}_{2}$ " was performed using $\mathrm{HCl}$ (35 vol\%), and tetraethyl orthosilicate (TEOS) obtained from Sigma Aldrich and used as-received. For the synthesis of s- $\mathrm{Fe}_{3} \mathrm{O}_{4}$ and $\mathrm{a}-\mathrm{Fe}_{2} \mathrm{O}_{3}, \mathrm{ACS}$ grade $\mathrm{FeCl}_{2} \cdot 4 \mathrm{H}_{2} \mathrm{O}, \mathrm{FeCl}_{3} \cdot 6 \mathrm{H}_{2} \mathrm{O}, \mathrm{Fe}\left(\mathrm{NO}_{3}\right)_{3}$ and $\mathrm{FeCl}_{3}$ purchased from Sigma Aldrich were used.

Simulated drinking water was prepared with the following ACS-grade chemicals (Sigma Aldrich): $\mathrm{NaHCO}_{3}$, $\mathrm{CaCl}_{2}, \mathrm{MgSO}_{4} \cdot 7 \mathrm{H}_{2} \mathrm{O}, \mathrm{Na}_{2} \mathrm{SiO}_{2} \cdot 9 \mathrm{H}_{2} \mathrm{O}, \mathrm{NaNO}_{3}, \mathrm{NaH}_{2} \mathrm{PO} \cdot \mathrm{H}_{2} \mathrm{O}$, and $\mathrm{NaF}$ (fluoride standard solution from Ricca Chemical). A single sodium arsenate standard $\left(\mathrm{Na}_{3} \mathrm{AsO}_{4}\right.$ in the form of an Atomic Adsorption Spectroscopy Arsenic Standard from Sigma Aldrich; $1000 \mathrm{mg} / \mathrm{L}$ As in $2 \%$ nitric acid prepared with high purity $\mathrm{As}_{2} \mathrm{O}_{3}, \mathrm{HNO}_{3}, \mathrm{NaOH}$, and $\mathrm{H}_{2} \mathrm{O}$ ) was used.

For the NEMI 3500 Fe-B iron detection method, $\mathrm{HCl}$ (35 vol\%), hydroxylamine, ammonium acetate, acetic acid, and 1,10-phenanthroline monohydrate were obtained from Sigma Aldrich and used as-received.

\subsection{Synthesis of $\mathrm{c}-\mathrm{Fe}_{3} \mathrm{O}_{4} @ \mathrm{SiO}_{2}$ nanopowders}

The c- $\mathrm{Fe}_{3} \mathrm{O}_{4} @ \mathrm{SiO}_{2}$ nanopowder was prepared as follows: $1 \mathrm{~g}$ of c- $-\mathrm{Fe}_{3} \mathrm{O}_{4}$ nanopowder was placed in $0.1 \mathrm{M} \mathrm{HCl}$ aqueous solution $(50 \mathrm{~mL}$ ) and ultrasonicated for $10 \mathrm{~min}$, magnetically separated and washed three times with DI water, and then dispersed in a solution of ethanol $(80 \mathrm{~mL}), \mathrm{DI}$ water $(20 \mathrm{~mL})$ and concentrated ammonia $(1.0 \mathrm{~mL}, 28 \mathrm{wt} \%$ aqueous solution). The $0.1 \mathrm{M} \mathrm{HCl}$ is to clean off the surface of the $\mathrm{c}-\mathrm{Fe}_{3} \mathrm{O}_{4}$ nanoparticles from any pre-existing impurities from the manufacture in order to prepare them for functionalization [54]. TEOS $(0.9 \mathrm{~g}, 4.32 \mathrm{mmol})$ was added immediately afterwards. The resulting mixture was stirred at room temperature for $12 \mathrm{~h}$, and the resulting solid product was magnetically collected, washed with ethanol and water three times, and dispersed in ethanol.

\subsection{Synthesis of $\mathrm{s}-\mathrm{Fe}_{3} \mathrm{O}_{4}$ and $\mathrm{a}-\mathrm{Fe}_{2} \mathrm{O}_{3}$ nanopowders}

$\mathrm{Fe}_{3} \mathrm{O}_{4}$ nanopowder was synthesized by dissolving $1.4 \mathrm{~g}$ of $\mathrm{FeCl}_{2} \cdot 4 \mathrm{H}_{2} \mathrm{O}$ and $2.7 \mathrm{~g}$ of $\mathrm{FeCl}_{3} \cdot 6 \mathrm{H}_{2} \mathrm{O}$ in $100 \mathrm{~mL}$ of DI water. The resulting solution was heated to $80^{\circ} \mathrm{C}$. Ammonium hydroxide ( $25 \mathrm{wt} \%$ ) was added dropwise until the nanopowder precipitated out of solution. After being separated from the solution with a neodymium magnet, the nanopowder was washed with $\mathrm{DI}$ water and ethanol and dried overnight under vacuum at $80{ }^{\circ} \mathrm{C}$ (synthesized $\mathrm{Fe}_{3} \mathrm{O}_{4}$ or "s- $\mathrm{Fe}_{3} \mathrm{O}_{4}$ "). The $a-\mathrm{Fe}_{2} \mathrm{O}_{3}$ nanopowder was synthesized from $\mathrm{Fe}\left(\mathrm{NO}_{3}\right)_{3}$ and $\mathrm{FeCl}_{3}$ through forced hydrolysis, as described in an earlier report [55].

\subsection{X-ray diffraction}

Each nanopowder was analyzed by powder $\mathrm{x}$-ray diffraction (XRD) using a Rigaku diffractometer with Cu Ka radiation $(1.5418 \AA)$. The data was collected from $3^{\circ}$ to $90^{\circ}$. The average crystallite size of each nanopowder was calculated using Scherrer's formula [56].

\subsection{X-ray photoelectron spectroscopy}

The atomic ratio of the $\mathrm{Fe}_{3} \mathrm{C} @ \mathrm{C}$ nanopowder was obtained from x-ray photoelectron spectroscopy (XPS) performed using a PHI Quantera SXM with an Al source (focused beam of $1.5 \mathrm{kV}, 25 \mathrm{~W}$ ). The pass energy of the survey spectra was $140 \mathrm{eV}$ with step size of $0.5 \mathrm{eV}$, while the one of atomic spectra was $26 \mathrm{eV}$ with step size of $0.1 \mathrm{eV}$. Each sample was dried and loaded to Al foil. XPS spectra was analyzed with MultiPak software. All peak positions were corrected based on C 1s at $284.8 \mathrm{eV}$.

\subsection{Nitrogen physisorption analysis}

The specific surface area of the nanopowders and the Bayoxide E33 powder was determined by first degassing each sample at $250^{\circ} \mathrm{C}$ under vacuum overnight. Once degassed, nitrogen adsorption-desorption isotherms were collected at $77 \mathrm{~K}$ using a QuantaChrome (Model \#AS3B) instrument. The specific surface area for each nanopowder was calculated with a standard five-point BET analysis method (P/ $P_{0}=0.10,0.15,0.20,0.25$, and 0.30 ). The pore size distribution and pore volume of the $\mathrm{Fe}_{3} \mathrm{C} @ \mathrm{C}$ nanopowder were determined from the adsorption branch of the nitrogen isotherms using the non-localized density functional theory (NLDFT) model [57].

\subsection{Magnetic measurements}

Magnetic characterization was conducted with the Superconducting Quantum Interference Device (SQUID) fitted 
with a MPMS XL (Quantum Design Inc.). For each hysteresis curve generated, the nanopowder was weighed, wrapped in Teflon tape, and analyzed at $27^{\circ} \mathrm{C}$ from -10 to $10 \mathrm{kOe}$.

Magnetic stability measurements were performed using $15 \mathrm{mg}$ of $\mathrm{c}-\mathrm{Fe}_{3} \mathrm{O}_{4}$ and $15 \mathrm{mg}$ of $\mathrm{Fe}_{3} \mathrm{C} @ \mathrm{C}$ placed into $15 \mathrm{~mL}$ of a solution of simulated drinking water. The resulting dispersions were then sonicated for $10 \mathrm{~min}$ and placed on a shake table for 4 weeks at $25^{\circ} \mathrm{C}$. Periodically, liquid aliquots were taken from the suspension and dried on Teflon tape under vacuum at $40^{\circ} \mathrm{C}$. The resulting dried nanopowders were weighed, wrapped in Teflon, and measured from -10 to $10 \mathrm{kOe}$ at $27^{\circ} \mathrm{C}$.

\subsection{Simulated drinking water preparation}

Simulated drinking water was prepared in accordance with the NSF 53 [58] challenge water by using the following salt concentrations: $\mathrm{NaHCO}_{3}(252 \mathrm{mg} / \mathrm{L}), \mathrm{CaCl}_{2}(147 \mathrm{mg} / \mathrm{L})$, $\mathrm{MgSO}_{4} \cdot 7 \mathrm{H}_{2} \mathrm{O}(124 \mathrm{mg} / \mathrm{L}), \mathrm{Na}_{2} \mathrm{SiO}_{3} \cdot 9 \mathrm{H}_{2} \mathrm{O}(95 \mathrm{mg} / \mathrm{L}), \mathrm{NaNO}_{3}$ (12 mg/L), NaF (2.2 mg/L), and $\mathrm{NaH}_{2} \mathrm{PO}_{4} \cdot \mathrm{H}_{2} \mathrm{O}(0.18 \mathrm{mg} / \mathrm{L})$. The solution was adjusted to $\mathrm{pH} 7.5$ using $\mathrm{HCl}(1.0 \mathrm{M})$. The resulting ionic strength and total dissolved solids (TDS) values were $8.5 \mathrm{mM}$ and $478 \mathrm{mg} / \mathrm{L}$, respectively.

\subsection{Stability batch tests}

The stability of the magnetic materials was assessed in simulated drinking water at $25^{\circ} \mathrm{C}$ and neutral $\mathrm{pH}(\sim 7.5)$, and also at an elevated temperature $\left(60^{\circ} \mathrm{C}\right)$ and neutral and low $\mathrm{pH}$ values $(\sim 7.5$ and $\sim 3)$ to accelerate any potential iron leaching. We chose the elevated temperature of 60 ${ }^{\circ} \mathrm{C}$, which was the temperature used by Sidhu et al. in their study of dissolution of iron oxides at low $\mathrm{pH}$ values [59]. The amount of dissolved iron for the stability tests was quantified with a Perkins Elmer Optima 8300 Inductively Coupled Plasma-Optical Emission Spectrometer (ICP-OES) and, separately, a colorimetric procedure adapted from the National Environmental Methods Index (NEMI). For ease of sample preparation and UV-vis photometric measurements, we primarily used the NEMI 3500 Fe-B (phenanthroline) method [52]. The $\mathrm{pH}$ of the bulk solution was adjusted to a desired $\mathrm{pH}(\sim 7.5$ or $\sim 3)$ with dropwise additions of $\mathrm{HCl}$ solution $(1.0 \mathrm{M})$, and the resulting solution was used immediately. An appropriate amount of water was combined with the desired nanopowder such that the final weight concentration of each nanopowder suspension was $500 \mathrm{mg} / \mathrm{L}$.

After sonication for $10 \mathrm{~min}, 2-\mathrm{mL}$ aliquots were taken from each sample, filtered with a $0.2-\mu \mathrm{m}$ PTFE syringe filter, and stored in 2-mL microcentrifuge tubes. The sonicated solutions were then placed inside a temperaturecontrolled shake table $\left(60^{\circ} \mathrm{C}\right.$, shaking speed of $\left.150 \mathrm{rpm}\right)$ for $24 \mathrm{~h}$. The suspension $\mathrm{pH}$ did not change during the 24-h period.

Liquid aliquots $(2 \mathrm{~mL})$ were extracted from each sample and filtered with a $0.2-\mu \mathrm{m}$ PTFE syringe filter. All samples were then analyzed for dissolved iron concentrations by using adapted procedures from the National Environmental Methods Index (NEMI). Specifically, the NEMI 3500 Fe-B (phenanthroline) method, which is well suited for field tests, was used [60]. For each sample, $1 \mathrm{~mL}$ was removed and combined with a solution containing $\mathrm{HCl}(40 \mu \mathrm{L}$; $38 \mathrm{wt} \%$ conc. aqueous solution), hydroxylamine $(20 \mu \mathrm{L}$, $22.14 \mathrm{mM})$, ammonium acetate buffer $(200 \mu \mathrm{L}, 587 \mathrm{mM})$, and phenanthroline solution $(80 \mu \mathrm{L}, 0.31 \mathrm{mM})$. The resulting solution (final $\mathrm{pH}$ of $\sim 3.3$ ) was vigorously agitated and then allowed to sit for $30 \mathrm{~min}$ before being analyzed with UV-vis spectroscopy at $510 \mathrm{~nm}$ (Shimazdu UV-2450 UV-Spectrophotometer).

\subsubsection{Arsenic adsorption experiments}

Batch arsenic equilibrium adsorption experiments were conducted in simulated drinking water at $25^{\circ} \mathrm{C}$. The initial $\mathrm{pH}$ value of the solution was set to $\sim 7.5$ and the initial concentration of arsenate was set to $\sim 50 \mu \mathrm{g}-\mathrm{As}(\mathrm{V}) / \mathrm{L}$. $\mathrm{Fe}_{3} \mathrm{C} @ \mathrm{C}$, $\mathrm{C}-\mathrm{Fe}_{3} \mathrm{O}_{4}$, and Bayoxide $\mathrm{E} 33$ were used as the adsorbent media. The adsorbent dosages ranged from 4 to $400 \mathrm{mg} / \mathrm{L}$. Experiments were conducted in LDPE wide-mouth bottles, and the samples were continuously agitated for $\sim 3$ days to ensure equilibrium. When collecting samples $(2 \mathrm{~mL})$ for analysis, the adsorbent was removed from the suspension via a $0.2-\mu \mathrm{m}$ Nylon syringe filter. The equilibrium waterphase concentration of arsenic was quantified using a tuned Thermo Scientific X-Series II Inductively Coupled Plasma Mass Spectrometer (ICP-MS) [52].

Adsorption data was fitted to linearized forms of the Freundlich (Eq. 1) and Langmuir (Eq. 2) isotherm models using the following equations:

$\log \left(q_{e}\right)=\log \left(K_{f}\right)+\frac{1}{n} \log \left(C_{e}\right)$

$\frac{1}{q_{e}}=\frac{1}{q_{m}}+\frac{1}{b q_{m} C_{e}}$

where $q_{e}$ is the adsorption capacity (units of $\mu \mathrm{g}$-adsorbate/ $g$-adsorbent), $K_{f}$ is the Freundlich adsorption capacity parameter (units of $\mu \mathrm{g}$-adsorbate/g-adsorbent)(mgadsorbate/ $\left.L)^{1 / n}\right), C_{e}$ is the equilibrium concentration of the contaminant (units of $\mu \mathrm{g}$-adsorbate/L), $n$ is the Freundlich affinity of adsorption parameter, $b$ is the adsorption equilibrium constant (units of $\mathrm{L} / \mu \mathrm{g}$-adsorbate), and $q_{m}$ is the maximum adsorption capacity (units of $\mu \mathrm{g}$-adsorbate/gadsorbent) as determined by the Langmuir isotherm 
fitting [61]. The "Freundlich derived" maximum adsorption capacity, $\mathrm{q}_{\mathrm{e}-\mathrm{max}}$, was determined using the largest measured adsorption capacity value taken from the Freundlich isotherm fitting.

\subsubsection{Magnetic column separation experiments}

Our benchtop magnetic capture unit was set up like a conventional high gradient magnetic separator (HGMS), permanent magnets were used instead of electromagnets $[26,62,63]$. A column packed with magnetically susceptible wires (e.g., stainless steel wool, SSW) causes an applied magnetic field to dehomogenize, producing large field gradients (regions where the magnetic field is no longer uniform) around the wires to attract magnetic particles to their surface. The strong magnetic forces produced by the large field gradients at the SSW wire surface are extremely effective at capturing fine particles $(<100$ microns) of weakly magnetic substances [64].

Our bench-top magnetic capture unit consisted of a cylindrical quartz column with an internal radius of $0.330 \mathrm{~cm}$ and a length of $12 \mathrm{~cm}$ (a total volume of $4.11 \mathrm{~cm}^{3}$ ) (Fig. 1). The $5-\mathrm{cm}$ bed length was filled with SSW (wire diameter of $50 \mu \mathrm{m}, 550 \mathrm{mg}$, grade 434 stainless steel), such that the bed density was $321.6 \mathrm{mg}-\mathrm{SSW} / \mathrm{cm}^{3}$ (void fraction $=0.96$ ). The column was placed in a $2-\mathrm{cm}$ gap between two permanent magnets housed within a rectangular steel frame. The total magnetic field strength produced was estimated to be within the range of 1.5-2.0 T (15-20 kOe).

A nanopowder suspension $(50 \mathrm{~mL})$ was pumped through the column at a desired flow rate $(1,3,5$, or $7 \mathrm{~mL} /$

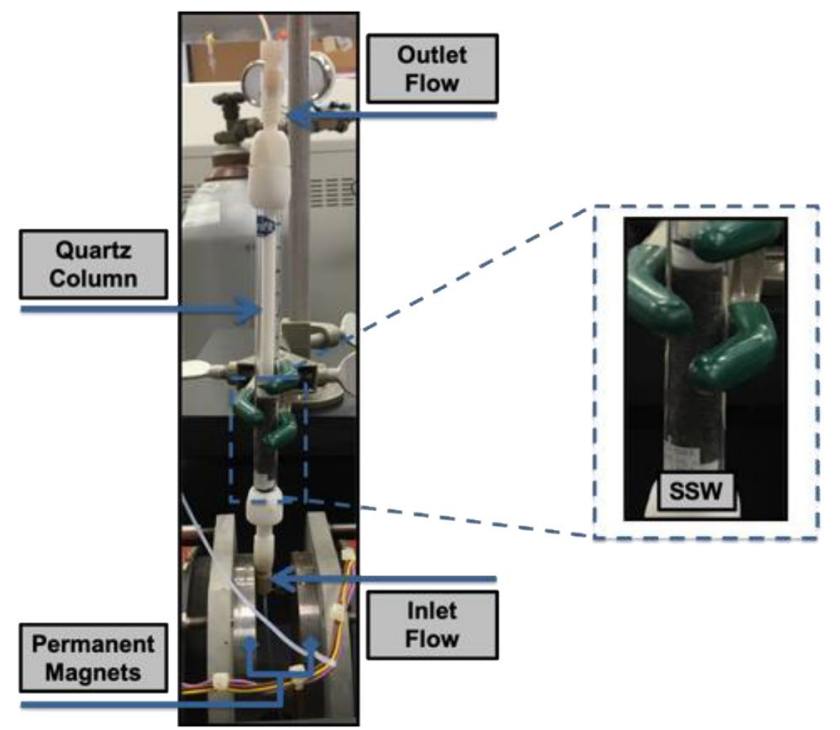

Fig. 1 The bench top magnetic capture unit with the quartz column (containing the stainless-steel wool, SSW) shown above and outside the two magnetic faces. Inset: Close-up of the SSW packing min) using a KD Scientific Syringe Pump System (Model number: 100, Series number: 4377). The empty bed contact time (volume EmptyBed $\div$ flow rate) for each flow rate was $1.71 \mathrm{~min}, 0.57 \mathrm{~min}, 0.34 \mathrm{~min}$, and $0.24 \mathrm{~min}$, respectively). The respective residence times (volume EmptyBed $\times$ (void fraction) $\div$ flow rate) were $1.64 \mathrm{~min}, 0.55 \mathrm{~min}, 0.33 \mathrm{~min}$, and $0.23 \mathrm{~min}$. A high inlet suspension concentration of $500 \mathrm{mg} / \mathrm{L}\left(362,467\right.$, and $350 \mathrm{mg} / \mathrm{L}-\mathrm{Fe}$ for $\mathrm{c}-\mathrm{Fe}_{3} \mathrm{O}_{4}, \mathrm{Fe}_{3} \mathrm{C} @ \mathrm{C}$, and $\mathrm{a}-\mathrm{Fe}_{2} \mathrm{O}_{3}$, respectively) was chosen to test the robustness of the magnetic capture unit. Collected periodically, the dissolved iron concentration in the effluent samples were analyzed with the NEMI Fe 3500-B method (Fig. S1).

\section{Results and discussion}

\subsection{Nanopowder characterization}

Figure 2 shows the $x$-ray diffraction (XRD) patterns for the nanopowders. The c- $\mathrm{Fe}_{3} \mathrm{O}_{4}, \mathrm{c}-\mathrm{Fe}_{3} \mathrm{O}_{4} @ \mathrm{SiO}_{2}$, and s- $\mathrm{Fe}_{3} \mathrm{O}_{4}$ materials were verified to have the magnetite $\mathrm{Fe}_{3} \mathrm{O}_{4}$ crystalline phase [65], with the $s-\mathrm{Fe}_{3} \mathrm{O}_{4}$ having a smaller grain size (Table 1). The silica content of c- $\mathrm{Fe}_{3} \mathrm{O}_{4} @ \mathrm{SiO}_{2}$ estimated to be $\sim 21 \mathrm{wt} \%$, based on molar ratios, indicating a thickness of $\sim 2 \mathrm{~nm}$ as detected through TEM (Fig. S2). The $\mathrm{a}-\mathrm{Fe}_{2} \mathrm{O}_{3}$ sample was verified to be the a phase of $\mathrm{Fe}_{2} \mathrm{O}_{3}$ (hematite) [66].

$\mathrm{The}_{\mathrm{Fe}} \mathrm{C} @ \mathrm{C}$ nanopowder has the cementite crystalline phase [34]. From x-ray photoelectron spectroscopy (XPS) analysis, the C:Fe atomic ratio of $\mathrm{Fe}_{3} \mathrm{C} @ \mathrm{C}$ is $2.08: 1$, which is higher than the $\mathrm{C}: \mathrm{Fe}$ atomic ratio for $\mathrm{Fe}_{3} \mathrm{C}(1: 3)$ due to the carbon coating. The coating accounts for $~ 14 \mathrm{wt} \%$ of the $\mathrm{Fe}_{3} \mathrm{C} @ \mathrm{C}$ material, suggesting $\sim 26$ monolayers of graphene (a single sheet is $0.34 \mathrm{~nm}$ thick) [57]. This closely matches the carbon coating thickness $(\sim 9 \mathrm{~nm})$ as detected through TEM (Fig. S3). As measured, $\mathrm{Fe}_{3} \mathrm{C} @ \mathrm{C}$ has a specific surface area (SSA) of $24.9 \mathrm{~m}^{2} / \mathrm{g}$ and (Table 2). In comparison, $\mathrm{C}-\mathrm{Fe}_{3} \mathrm{O}_{4}$ displayed superparamagnetic-like behavior, with its low magnetic remanence $\left(M_{r}\right)$ and coercivity $\left(H_{c}\right)$ values (Fig. 3, Table 1) [67, 68]. The magnetic saturation $\left(\mathrm{M}_{\mathrm{s}}\right)$ of $\mathrm{c}-\mathrm{Fe}_{3} \mathrm{O}_{4}$ and $\mathrm{c}-\mathrm{Fe}_{3} \mathrm{O}_{4} @ \mathrm{SiO}_{2}$ were $77.1 \mathrm{emu} / \mathrm{g}$ and $54.4 \mathrm{emu} / \mathrm{g}$, respectively.

Even after normalizing to only the $\mathrm{Fe}_{3} \mathrm{O}_{4}$ content (77.1 emu/g- $\mathrm{Fe}_{3} \mathrm{O}_{4}$ and $68.9 \mathrm{emu} / \mathrm{g}-\mathrm{Fe}_{3} \mathrm{O}_{4}$ ), the magnetic saturation was lower after coating, which is possibly due to surface spin disorder caused by the silica shell and the interactions between the non-magnetic $\mathrm{SiO}_{2}$ atoms and the magnetic $\mathrm{c}-\mathrm{Fe}_{3} \mathrm{O}_{4}$ atoms $[65,69,70]$. In addition, the c- $\mathrm{Fe}_{3} \mathrm{O}_{4} @ \mathrm{SiO}_{2}$ had greater magnetic remanence and coercivity values than $\mathrm{c}-\mathrm{Fe}_{3} \mathrm{O}_{4}$, due to the presence of its $\mathrm{SiO}_{2}$ shell [71]. The $\mathrm{s}-\mathrm{Fe}_{3} \mathrm{O}_{4}$, had a similar magnetic saturation to that of the $\mathrm{c}-\mathrm{Fe}_{3} \mathrm{O}_{4}$, but had lower magnetic remanence and coercivity values. $\mathrm{Fe}_{3} \mathrm{C} @ \mathrm{C}$ had the 
Fig. 2 XRD patterns for $\mathrm{Fe}_{3} \mathrm{C} @ \mathrm{C}$ (green), $\mathrm{c}-\mathrm{Fe}_{3} \mathrm{O}_{4}$ (blue), $\mathrm{c}-\mathrm{Fe}_{3} \mathrm{O}_{4} @ \mathrm{SiO}_{2}$ (orange), s- $\mathrm{Fe}_{3} \mathrm{O}_{4}$ (red), and $\mathrm{a}-\mathrm{Fe}_{2} \mathrm{O}_{3}$ (gray) nanopowders

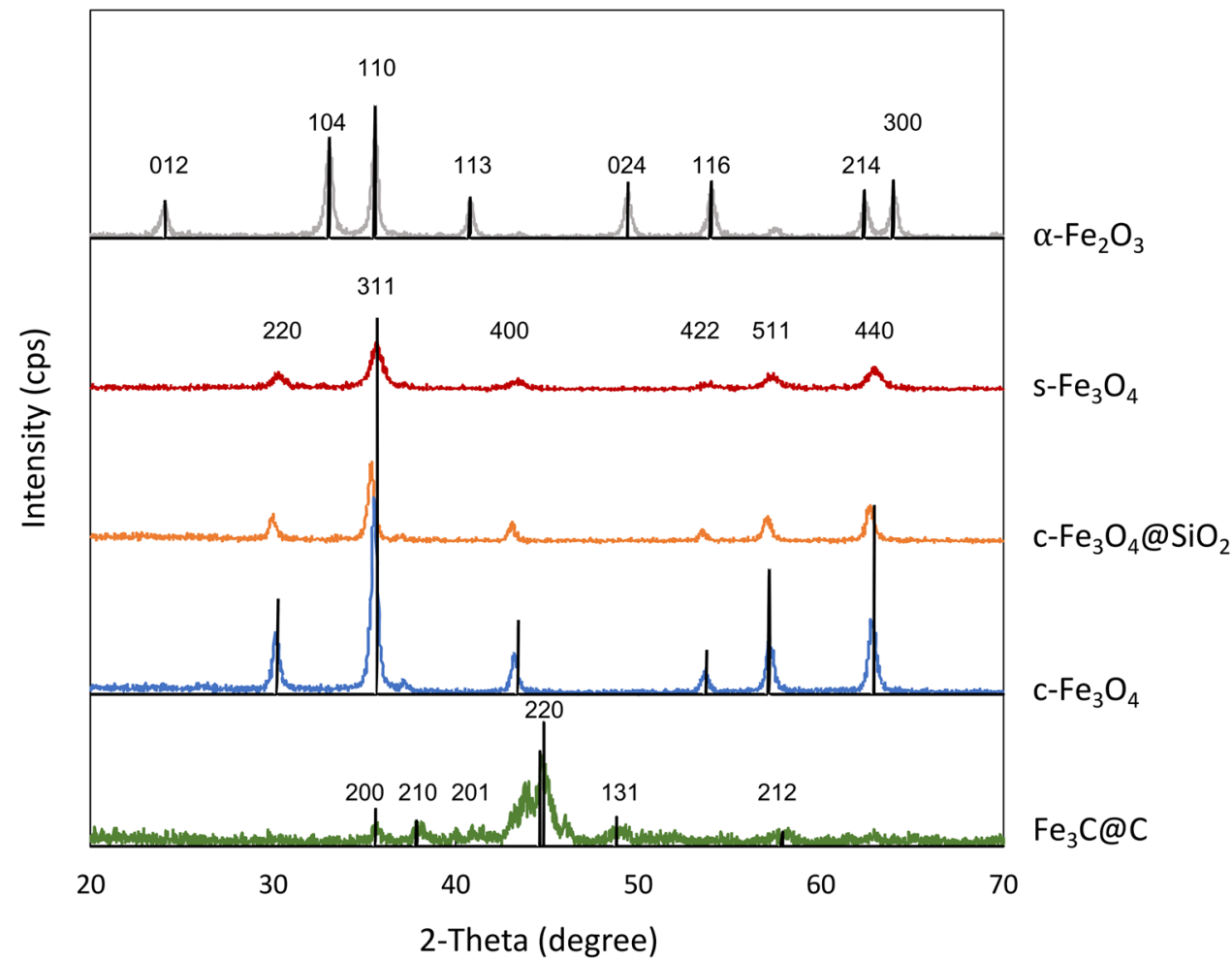

\begin{tabular}{lllllll}
\hline Nanopowders & $d_{\text {XRD }}(\mathrm{nm})$ & $\mathrm{SSA}\left(\mathrm{m}^{2} / \mathrm{g}\right)$ & $\mathrm{M}_{\mathrm{s}}(\mathrm{emu} / \mathrm{g})$ & $\mathrm{M}_{\mathrm{r}}(\mathrm{emu} / \mathrm{g})$ & $\mathrm{M}_{\mathrm{r}} / \mathrm{M}_{\mathrm{s}}$ & $\mathrm{H}_{\mathrm{c}}(\mathrm{Oe})$ \\
\hline $\mathrm{Fe}_{3} \mathrm{C} @ \mathrm{C}^{\mathrm{a}}$ & 11 & 24.9 & 138.2 & 20.6 & 0.161 & 200 \\
$\mathrm{c}-\mathrm{Fe}_{3} \mathrm{O}_{4}{ }^{\mathrm{b}}$ & 22 & 44.2 & 77.1 & 8.06 & 0.105 & 80 \\
$\mathrm{c}^{-} \mathrm{Fe}_{3} \mathrm{O}_{4} @ \mathrm{SiO}_{2}{ }^{\mathrm{b}}$ & 22 & 15.5 & 54.4 & 9.00 & 0.165 & 160 \\
$\mathrm{~s}-\mathrm{Fe}_{3} \mathrm{O}_{4}{ }^{\mathrm{b}}$ & 11 & 54.5 & 70.0 & 1.08 & 0.015 & 4 \\
$\mathrm{a}-\mathrm{Fe}_{2} \mathrm{O}_{3}{ }^{\mathrm{c}}$ & 32 & 55.4 & $\mathrm{n} / \mathrm{d}$ & 0.196 & $\mathrm{n} / \mathrm{d}$ & 2.75 \\
\hline
\end{tabular}

${ }^{\mathrm{a}}$ Ferromagnetic [30]

${ }^{b}$ Ferrimagnetic [30]

${ }^{\mathrm{C}}$ Antiferromagnetic [30]

\begin{tabular}{|c|c|c|c|c|}
\hline \multirow[t]{2}{*}{ Nanopowders } & \multicolumn{2}{|c|}{$25^{\circ} \mathrm{C}\left(\right.$ or $\left.60^{\circ} \mathrm{C}\right)$ and $\mathrm{pH} 7.5$} & \multicolumn{2}{|l|}{$60^{\circ} \mathrm{C}$ and $\mathrm{pH} 3$} \\
\hline & $\begin{array}{l}{[\mathrm{Fe}](\mathrm{mg} / \mathrm{L})} \\
\text { Time }=0 \text { day }\end{array}$ & $\begin{array}{l}{[\mathrm{Fe}](\mathrm{mg} / \mathrm{L})} \\
\text { Time }=1 \text { day }\end{array}$ & $\begin{array}{l}{[\mathrm{Fe}](\mathrm{mg} / \mathrm{L})} \\
\text { Time }=0 \text { days }\end{array}$ & $\begin{array}{l}{[\mathrm{Fe}](\mathrm{mg} / \mathrm{L})} \\
\text { Time }=1 \text { day }\end{array}$ \\
\hline $\mathrm{Fe}_{3} \mathrm{C} @ \mathrm{C}$ & $\mathrm{BD}$ & $\mathrm{BD}$ & $7.89 \pm 1.4$ & $9.34 \pm 0.04$ \\
\hline $\mathrm{c}-\mathrm{Fe}_{3} \mathrm{O}_{4}$ & $\mathrm{BD}$ & $\mathrm{BD}$ & $\mathrm{BD}$ & $0.69 \pm 0.09$ \\
\hline $\mathrm{c}-\mathrm{Fe}_{3} \mathrm{O}_{4} @ \mathrm{SiO}_{2}$ & $\mathrm{BD}$ & $\mathrm{BD}$ & $\mathrm{BD}$ & $\mathrm{BD}$ \\
\hline $\mathrm{s}-\mathrm{Fe}_{3} \mathrm{O}_{4}$ & $\mathrm{BD}$ & $\mathrm{BD}$ & $0.24 \pm 0.03$ & $0.82 \pm 0.06$ \\
\hline $\mathrm{a}-\mathrm{Fe}_{2} \mathrm{O}_{3}$ & $\mathrm{BD}$ & $\mathrm{BD}$ & $\mathrm{BD}$ & $\mathrm{BD}$ \\
\hline
\end{tabular}

$\mathrm{BD}$ denotes below the detection level of the calibration curve from the NEMI 3500 Fe-B method (i.e. $0.1 \mathrm{mg} / \mathrm{L})$ highest magnetic saturation of all the iron-based nanopowders analyzed, with a measured magnetic saturation value of $138.2 \mathrm{emu} / \mathrm{g}$, slightly lower than the value for bulk
$\mathrm{Fe}_{3} \mathrm{C}\left(\mathrm{M}_{\mathrm{s}} \sim 140 \mathrm{emu} / \mathrm{g}\right)$ [35] and 80\% higher than that for c- $-\mathrm{Fe}_{3} \mathrm{O}_{4}$. $\mathrm{Fe}_{3} \mathrm{C} @ \mathrm{C}$ has a higher $\mathrm{Ms}$ than $\mathrm{c}-\mathrm{Fe}_{3} \mathrm{O}_{4}$ because it has more iron and less oxygen; a materials magnetic 


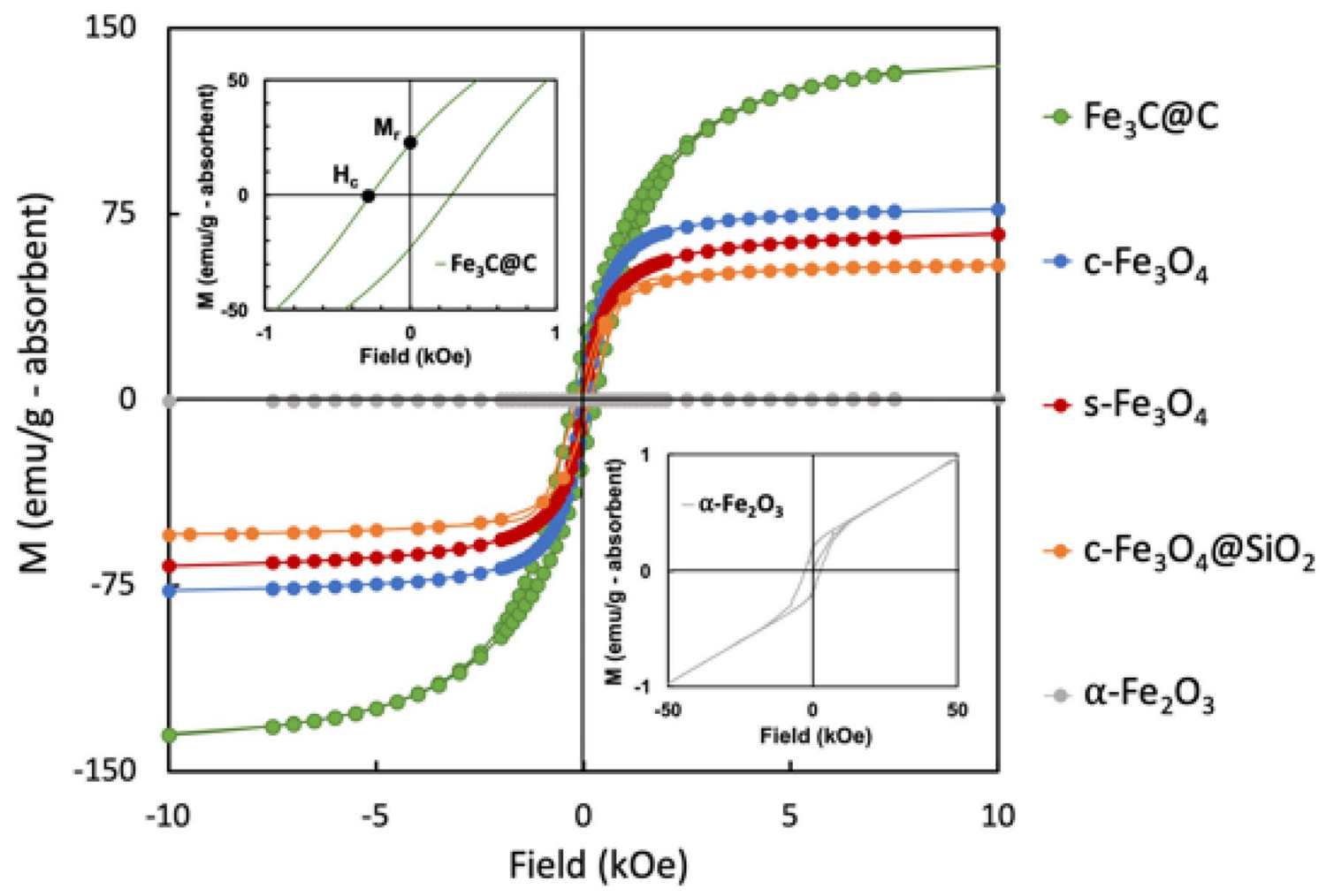

Fig. 3 Magnetization curves for $\mathrm{Fe}_{3} \mathrm{C} @ \mathrm{C}$ (green), c- $\mathrm{Fe}_{3} \mathrm{O}_{4}$ (blue), $\mathrm{c}-\mathrm{Fe}_{3} \mathrm{O}_{4} @ \mathrm{SiO}_{2}$ (orange), s- $\mathrm{Fe}_{3} \mathrm{O}_{4}$ (red), and a- $\mathrm{Fe}_{2} \mathrm{O}_{3}$ (gray) nanopowders, at $27^{\circ} \mathrm{C}$ from $-10 \mathrm{kOe}$ to $10 \mathrm{kOe}$. Inset top left: zoomed-in view of the magnetization curve for the $\mathrm{Fe}_{3} \mathrm{C} @ \mathrm{C}$ nanopowders with the

saturation capacity is dependent upon the individual atoms that comprise the material and the arraignment of those atoms. $\mathrm{Fe}_{3} \mathrm{C}$ contains mostly iron ( $93.3 \mathrm{wt} \%$ iron) whereas $\sim 72$ wt $\%$ of $\mathrm{Fe}_{3} \mathrm{O}_{4}$ is iron. Oxygen has a lower magnetic moment (i.e., a single oxygen molecule has a magnetic moment of 2.85 bohr magnetons) than iron (i.e., 5.92 bohr magnetons).

The ratio of magnetic remanence to magnetic saturation $\left(M_{r} / M_{s}\right)$ indicates the extent of ferromagnetism. $\mathrm{s}-\mathrm{Fe}_{3} \mathrm{O}_{4}$ can be considered less ferromagnetic (or more superparamagnetic, $\left.\mathrm{M}_{\mathrm{r}} / \mathrm{M}_{\mathrm{s}}=0.015\right)$ than $\mathrm{c}-\mathrm{Fe}_{3} \mathrm{O}_{4}\left(\mathrm{M}_{\mathrm{r}} /\right.$ $\left.M_{s}=0.105\right)$, consistent with its smaller grain size [29]. To contrast, a- $\mathrm{Fe}_{2} \mathrm{O}_{3}$ is antiferromagnetic [30] and did not reach magnetic saturation within the magnetic field range of $-50 \mathrm{kOe}$ to $50 \mathrm{kOe}$ (Fig. 3, inset). Being technically a ferromagnetic material, $\mathrm{Fe}_{3} \mathrm{C} @ \mathrm{C}$ can be considered to have superparamagnetic-like property $\left(\mathrm{M}_{\mathrm{r}} / \mathrm{M}_{\mathrm{s}}=0.161\right)$ as $c-\mathrm{Fe}_{3} \mathrm{O}_{4} @ \mathrm{SiO}_{2}\left(\mathrm{M}_{\mathrm{r}} / \mathrm{M}_{\mathrm{s}}=0.165\right)$.

Within error $( \pm 9.59 \mathrm{emu} / \mathrm{g})$, the $\mathrm{c}-\mathrm{Fe}_{3} \mathrm{O}_{4}$ and the $\mathrm{Fe}_{3} \mathrm{C} @ \mathrm{C}$ nanopowders were magnetically unchanged after one month of being immersed in simulated drinking water $(\mathrm{pH} \sim 8.5)$ and $\mathrm{DI}$ water $(\mathrm{pH} \sim 6.5)$ at room temperature, indicating structural stability and a lack of iron leaching (Tables S1-S2). magnetic remanence $\left(M_{r}\right)$ and coercivity $\left(H_{c}\right)$ labeled. Inset bottom right: Magnetization curve for $\mathrm{a}-\mathrm{Fe}_{2} \mathrm{O}_{3}$ at $27^{\circ} \mathrm{C}$ from -50 kOe to 50 kOe

\subsection{Iron leaching behavior in simulated drinking water}

For all nanopowders tested at room temperature in simulated drinking water, the amount of dissolved iron found after the 24-h testing window was below the ICPOES detection limit ( $<0.1 \mathrm{mg} / \mathrm{L}$ ) (Table 2 ). Dissolved iron was also not detected when the samples were subjected to testing at $60^{\circ} \mathrm{C}$ (Table 2 ).

Under the more aggressive acidic water condition for accelerated testing, $\mathrm{c}-\mathrm{Fe}_{3} \mathrm{O}_{4}$ and $\mathrm{s}-\mathrm{Fe}_{3} \mathrm{O}_{4}$ both leached significantly due to low-pH dissolution $\left(\mathrm{FeOOH}+3 \mathrm{HCl} \rightarrow \mathrm{FeCl}^{2+}+2 \mathrm{Cl}^{-}+2 \mathrm{H}_{2} \mathrm{O}\right)$. Dissolved iron levels reached $0.69 \mathrm{mg} / \mathrm{L}$ and $0.82 \mathrm{mg} / \mathrm{L}$, respectively (Table 2) [72]. $\alpha-\mathrm{Fe}_{2} \mathrm{O}_{3}$ also leached, but the extent of iron leaching was considerably less; of all iron oxides, hematite is the most stable [59]. Dissolved iron concentrations were monitored at the beginning of the leaching experiments (i.e., immediately after the nanopowders were added to the room temperature solution) also. Roughly $30 \%$ of the total amount of leached iron from s- $\mathrm{Fe}_{3} \mathrm{O}_{4}$ was released initially. Coating c- $\mathrm{Fe}_{3} \mathrm{O}_{4}$ with $\mathrm{SiO}_{2}$ is well noted in literature to reduce and even prevent leaching 
[73]. Over the 24-h period, no leaching was detected for c- $\mathrm{Fe}_{3} \mathrm{O}_{4} @ \mathrm{SiO}_{2}$ (Table 2).

It was hypothesized that $\mathrm{Fe}_{3} \mathrm{C} @ \mathrm{C}$ would behave similarly to $\mathrm{c}-\mathrm{Fe}_{3} \mathrm{O}_{4} @ \mathrm{SiO}_{2}$ since both have a protective coating. However, $\mathrm{Fe}_{3} \mathrm{C} @ \mathrm{C}$ leached significantly at $\mathrm{pH} 3$ after $24 \mathrm{~h}$ (Table 2). It leached significantly at the beginning of the leaching experiment also, releasing $>80 \%$ of the total dissolved iron. While the protective carbon coating of the $\mathrm{Fe}_{3} \mathrm{C} @ \mathrm{C}$ fully covers the $\mathrm{Fe}_{3} \mathrm{C}$ core, the leaching might be attributable to its detected porosity (PSD of $\sim 40 \mathrm{~nm}$ and $\mathrm{PV} \sim 0.04 \mathrm{~cm}^{3} / \mathrm{g}$ from $\mathrm{N}_{2}$ adsorption measurements), which would allow the acid to reach the $\mathrm{Fe}_{3} \mathrm{C}$ core.

\subsection{Arsenic adsorption experiments}

Arsenic equilibrium adsorption data for $\mathrm{Fe}_{3} \mathrm{C} @ \mathrm{C}$ and $\mathrm{c}-\mathrm{Fe}_{3} \mathrm{O}_{4}$ were fit to the Freundlich isotherm model (Fig. 4, Table 3) and the Langmuir isotherm model (Fig. S5, Table S3). In literature, activated carbon and graphenebased materials have been shown to remove arsenic, although the process and optimal conditions for arsenic

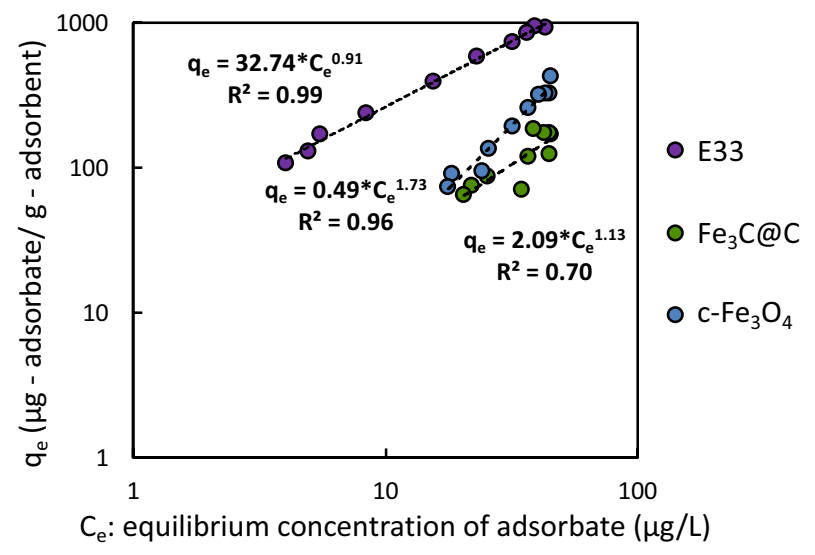

Fig. 4 Freundlich isotherm fittings for arsenic equilibrium adsorption within simulated drinking water after a contact time of 3 days for Bayoxide $\mathrm{E} 33$ (purple), $\mathrm{Fe}_{3} \mathrm{C} @ \mathrm{C}$ (green), and c- $\mathrm{Fe}_{3} \mathrm{O}_{4}$ (blue) at a $\mathrm{pH}$ of $\sim 7.5$. Initial As concentration $\left(\mathrm{C}_{0-\mathrm{As}}\right) \sim 50 \mu \mathrm{g} / \mathrm{L}$. Absorbent dosage range for Bayoxide $\mathrm{E} 33, \mathrm{Fe}_{3} \mathrm{C} @ \mathrm{C}$, and $\mathrm{c}-\mathrm{Fe}_{3} \mathrm{O}_{4}: 4 \mathrm{mg} / \mathrm{L}$ to $400 \mathrm{mg} / \mathrm{L}$. Note: no iron leaching was detected for any of the adsorbents via ICP-MS adsorption remain unclear [74-76]. In our studies, $\mathrm{Fe}_{3} \mathrm{C} @ \mathrm{C}$ shows slight adsorption aversion for the negatively charged arsenate species (i.e., $\mathrm{H}_{2} \mathrm{AsO}_{4}{ }^{-}$and $\mathrm{HAsO}_{4}{ }^{2-}$ ) common in groundwaters - as indicated by its Freundlich adsorption affinity parameter $(1 / n=1.13)$ being greater than 1 . Surface chemistry is critical in arsenic removal by metal oxide species with electrostatic attraction between the anionic arsenic species being favored on positive surfaces. The $\mathrm{pH}$ of zero point of charge or the isoelectric point can be an indicator of the removal of anionic arsenic species [52]. Given the negatively charged carbon surface of $\mathrm{Fe}_{3} \mathrm{C} @ \mathrm{C}$ at $\mathrm{pH} \sim 7.5$, the anionic arsenate species would be averse to adsorbing onto its surface (Fig. S4; isoelectric point (IEP) of $\mathrm{Fe}_{3} \mathrm{C} @ \mathrm{C} \sim 4.2$ ). Despite this aversion between the negatively charged carbon surface and the anionic arsenate species, an appreciable arsenic adsorption capacity emerges for $\mathrm{Fe}_{3} \mathrm{C} @ \mathrm{C}$. Much like in other porous materials (i.e., iron, aluminum, titanium, zirconia, etc.), the anionic arsenate species diffuses through the porous carbon coating of $\mathrm{Fe}_{3} \mathrm{C} @ \mathrm{C}$ (porosity: PSD of $\sim 40 \mathrm{~nm}$ and $\mathrm{PV} \sim 0.04 \mathrm{~cm}^{3} / \mathrm{g}$ ) and adsorbs onto the positively charged (i.e., IEP 10) iron-carbide core [77].

$\mathrm{Fe}_{3} \mathrm{C} @ \mathrm{C}$ was benchmarked against c- $\mathrm{Fe}_{3} \mathrm{O}_{4} \cdot \mathrm{c}-\mathrm{Fe}_{3} \mathrm{O}_{4}$ adsorbed $1.4 \times$ more arsenic by mass than $\mathrm{Fe}_{3} \mathrm{C} @ \mathrm{C}$ at an equilibrium concentration $C_{e}$ of $20 \mu \mathrm{g} / \mathrm{L}$, and $\sim 2 \times$ more arsenic at $C_{e} \sim 40 \mu \mathrm{g} / \mathrm{L}$. When normalized to surface area, the maximum arsenic adsorption capacity of $\mathrm{Fe}_{3} \mathrm{C} @ \mathrm{C}$ was $\sim 70 \%$ of $c-\mathrm{Fe}_{3} \mathrm{O}_{4}[11]\left(\mathrm{q}_{\mathrm{e}-\text { max-ssA }}=9.62\right.$ vs. $6.75 \mu \mathrm{g} /$ $\mathrm{m}^{2}$, respectively), which was less due to differences in arsenic affinity. As a nonmagnetic comparison material and as a commonly used As adsorbent, Bayoxide E33 adsorbed $\sim 9 \times$ more arsenic on a mass basis than $\mathrm{Fe}_{3} \mathrm{C} @ \mathrm{C}$ at an equilibrium arsenic concentration $C_{e}$ of $20 \mu \mathrm{g} / \mathrm{L}$ and $\sim 5 \times$ more arsenic at $C_{e} \sim 40 \mu \mathrm{g} / \mathrm{L}$, due to greater arsenic affinity and a $4.8 \times$ higher surface area. When normalized to surface area, the arsenic adsorption capacity of $\mathrm{Fe}_{3} \mathrm{C} @ \mathrm{C}$ was closer (88\%) to that of Bayoxide E33 ( $\mathrm{q}_{\mathrm{e}-\mathrm{max}-\mathrm{SSA}}=6.75 \mathrm{vs} .7 .67 \mathrm{mg} / \mathrm{m}^{2}$, respectively).

We gained limited insights by fitting the equilibrium adsorption data to a Langmuir model. Fitted values for the Langmuir constant and the maximum sorption capacity were negative for $\mathrm{Fe}_{3} \mathrm{C} @ \mathrm{C}$, indicating that the

Table 3 Freundlich parameters for arsenic adsorption

\begin{tabular}{llllll}
\hline Adsorbent & $\begin{array}{l}K_{f} \text { : Freundlich Adsorption } \\
\text { Capacity Parameter }(\mu \mathrm{g} / \mathrm{g}) \\
(\mu \mathrm{g} / \mathrm{L})^{-1 / \mathrm{n}}\end{array}$ & $\begin{array}{l}\text { Specific } \\
\text { Surface Area } \\
\left(\mathrm{m}^{2} / \mathrm{g}\right)\end{array}$ & $\begin{array}{l}\text { 1/n: Freundlich Affinity } \\
\text { of Adsorption Parameter }\end{array}$ & $\begin{array}{l}\mathrm{q}_{\mathrm{e}-\mathrm{max}} \text { : As Adsorption } \\
\text { Capacity }(\mu \mathrm{g} / \mathrm{g} \text { of adsor- } \\
\text { bent })\end{array}$ & $\begin{array}{l}\mathrm{q}_{\mathrm{e}-\mathrm{max}-\mathrm{SSA}: \text { Normalized }} \\
\text { As Adsorption }\left(\mu \mathrm{g} / \mathrm{m}^{2}\right)\end{array}$ \\
\hline $\mathrm{E} 33$ & 32.75 & 120.0 & 0.906 & 920 & 7.67 \\
$\mathrm{Fe}_{3} \mathrm{C} @ \mathrm{C}$ & 2.095 & 24.9 & 1.13 & 168 & 6.75 \\
$\mathrm{C}-\mathrm{Fe}_{3} \mathrm{O}_{4}$ & 0.491 & 44.2 & 1.73 & 425 & 9.62 \\
\hline
\end{tabular}

Maximum adsorption capacity $\left(q_{e-\max }\right)$ measured at $C_{e}=50 \mu \mathrm{g} / \mathrm{L}$ 
Table $4 \%$ Magnetic recovery for $\mathrm{Fe}_{3} \mathrm{C} @ \mathrm{C}$ and c- $\mathrm{Fe}_{3} \mathrm{O}_{4}$ nanopowders $(500 \mathrm{mg} / \mathrm{L}, 50 \mathrm{~mL}$ total volume) in simulated drinking water at $\mathrm{pH} \sim 7.5$. Influent $\mathrm{c}-\mathrm{Fe}_{3} \mathrm{O}_{4}$ and $\mathrm{Fe}_{3} \mathrm{C} @ \mathrm{C}$ nanopowder suspensions were $362 \mathrm{mg} / \mathrm{L}$ and $467 \mathrm{mg} / \mathrm{L}$, respectively

\begin{tabular}{llll}
\hline $\begin{array}{l}\text { Flow rate } \\
(\mathrm{mL} / \mathrm{min})\end{array}$ & $\begin{array}{l}\text { Residence } \\
\text { time }(\mathrm{min})\end{array}$ & $\begin{array}{l}\text { Total dissolved iron } \\
\text { in effluent }\left(\mathrm{Fe}_{3} \mathrm{C} @ \mathrm{C}\right) \\
(\mathrm{mg} / \mathrm{L})\end{array}$ & $\begin{array}{l}\text { Total dissolved iron } \\
\text { in effluent }\left(\mathrm{c}-\mathrm{Fe}_{3} \mathrm{O}_{4}\right) \\
(\mathrm{mg} / \mathrm{L})\end{array}$ \\
\hline 1 & 1.64 & $\mathrm{BD}$ & $\mathrm{BD}$ \\
3 & 0.55 & $\mathrm{BD}$ & $\mathrm{BD}$ \\
5 & 0.33 & $0.13 \pm 0.02$ & $\mathrm{BD}$ \\
7 & 0.23 & $\mathrm{BD}$ & $\mathrm{BD}$ \\
\hline
\end{tabular}

$\mathrm{BD}$ denotes below the detection level of the calibration curve from the NEMI $3500 \mathrm{Fe}-\mathrm{B}$ method $(0.1 \mathrm{mg} / \mathrm{L})$

monolayer adsorption assumption of the model did not apply for arsenic adsorbing onto this nanopowder (Table S3). Multilayer adsorption of arsenic seems to play more of a role in arsenic adsorption onto the surface of $\mathrm{Fe}_{3} \mathrm{C} @ \mathrm{C}$ because of its porous nature [78]. The fitted values for the Langmuir constant and the maximum sorption capacity for $\mathrm{c}-\mathrm{Fe}_{3} \mathrm{O}_{4}$ were negative also. On the other hand, the Langmuir model applied to Bayoxide E33 material; its maximum As adsorption capacity was $5 \mathrm{mg} / \mathrm{g}\left(=41.7 \mu \mathrm{g} / \mathrm{m}^{2}\right)$ (Table S3, Table 3).

\subsection{Magnetic separation flow results}

The removability of the $\mathrm{Fe}_{3} \mathrm{C} @ \mathrm{C}$ nanopowder suspended in simulated drinking was tested at different flow conditions in the bench-top magnetic capture unit. Effluent samples were collected and acidified, and any non-captured nanopowder was quantified using the NEMI 3500-B method. For the $\mathrm{Fe}_{3} \mathrm{C} @ \mathrm{C}$ nanopowder, the total dissolved iron levels in the effluent were below the US EPA secondary maximum contaminant level $(\mathrm{SMCL} \leq 0.3 \mathrm{mg} / \mathrm{L})$ at all flow rates tested, and below or near the lower limit of detection $(0.1 \mathrm{mg} / \mathrm{L})$ (Table 4, Table S4). The low $\mathrm{Fe}_{3} \mathrm{C} @ \mathrm{C}$ concentrations in the effluent should not raise much toxicity concerns, as the $\mathrm{Fe}_{3} \mathrm{C} @ \mathrm{C}$ composition is being studied for biomedical applications [79]. For the comparison material, $\mathrm{c}-\mathrm{Fe}_{3} \mathrm{O}_{4}$ nanopowder, the total dissolved iron levels were below the $S M C L$ and below detection limit $(<0.1 \mathrm{mg} / \mathrm{L})$. Both magnetic nanopowders were successfully magnetically captured from simulated drinking water regardless of contact time for the tested flow rates below. To explore the applicability of $\mathrm{Fe}_{3} \mathrm{C} @ \mathrm{C}$ for larger water treatment schemes, a magnetic capturing unit that can accommodate larger volumes and higher flow rates of water is being developed.

\section{Conclusion}

The aim of this work was to quantify the stability, magnetic separation, and arsenic adsorptive properties of nanostructured carbon-coated iron carbide ("Fe $\mathrm{C}_{3} \mathrm{CC}$ ") in simulated drinking water for the first time to address long-standing issues of magnetic recoverability and martial integrity of iron-based adsorbents in drinking water sources. $\mathrm{Fe}_{3} \mathrm{C} @ \mathrm{C}$ is highly magnetic, with a magnetic saturation value that is at least $80 \%$ higher than that of $\mathrm{Fe}_{3} \mathrm{O}_{4}$ nanopowders. It retains its chemical integrity and superparamagnetic-like property in simulated drinking water, and it is completely removable using a permanent magnet flow device (i.e., we were able to achieve a percent removal of $>99 \%$ using an in-house magnetic separation column). While it adsorbs arsenic with a surface-area-normalized capacity that is modestly lower compared to Bayoxide $\mathrm{E} 33$ goethite (by 12\%) and $\mathrm{Fe}_{3} \mathrm{O}_{4}$ (by 30\%), $\mathrm{Fe}_{3} \mathrm{C} @ \mathrm{C}$ is magnetically recoverable (whereas Bayoxide $\mathrm{E} 33$ is not). This paper demonstrates the ability of $\mathrm{Fe}_{3} \mathrm{C} @ \mathrm{C}$ to provide a functionalizable carbon surface (that $\mathrm{Fe}_{3} \mathrm{O}_{4}$ does not have), to remove arsenic and plausibly other contaminants from drinking water sources.

Acknowledgements This work was supported by the National Science Foundation (EEC-1449500) Nanosystems Engineering Research Center on Nanotechnology-Enabled Water Treatment. The authors thank Dr. K. N. Heck and Ms. M. Marcos for conducting BET measurements, Ms. Y. Xu for conducting XPS measurements, and Mr. R. Turley for conducting ICP-OES measurements. The authors wish to acknowledge the staff and facilities of the Shared Equipment Authority at Rice University, and Dr. T. Shen at Nanostructured \& Amorphous Materials Inc. for helpful discussions about the $\mathrm{Fe}_{3} \mathrm{C} @ \mathrm{C}$ nanopowder.

Author contributions CDP. and MSW conceived of the experimental plan. CDP and LMG. conducted the methylene blue and arsenic adsorption experiments. CDP conducted the materials characterization and magnetic column separation experiments. CAC analyzed and conducted $\mathrm{N}_{2}$ adsorption measurements of the $\mathrm{Fe}_{3} \mathrm{C} @ \mathrm{C}$ nanopowder. KV, AWL, and SG synthesized the $\mathrm{s}-\mathrm{Fe}_{3} \mathrm{O}_{4}$ nanopowder, $\mathrm{a}-\mathrm{Fe}_{2} \mathrm{O}_{3}$ nanopowder, and the $\mathrm{c}-\mathrm{Fe}_{3} \mathrm{O}_{4} @ \mathrm{SiO}_{2}$ nanopowder respectively. PW developed arsenic adsorption methodology. AJA. conducted ICP-MS for the arsenic adsorption experiments. All authors (CDP, SG, LMG, $\mathrm{KV}, \mathrm{AWL}, \mathrm{CAC}, \mathrm{AJA}, \mathrm{DV}, \mathrm{JBZ}, \mathrm{PW}, \mathrm{MSW}$ ) contributed to data analysis and manuscript preparation.

Funding This work was supported by the National Science Foundation (EEC-1449500) Nanosystems Engineering Research Center on Nanotechnology-Enabled Water Treatment.

\section{Compliance with ethical standards}

Conflict of interest There are no conflicts to declare.

\section{References}

1. Su C (2017) Environmental implications and applications of engineered nanoscale magnetite and its hybrid nanocomposites: a 
review of recent literature. J Hazard Mater 322:48-84. https:// doi.org/10.1016/j.jhazmat.2016.06.060

2. Jun Y, Choi J, Cheon J (2007) Heterostructured magnetic nanoparticles: their versatility and high performance capabilities. Chem Commun. https://doi.org/10.1039/B614735F

3. Zhao Y, Li J, Zhao L et al (2014) Synthesis of amidoxime-functionalized Fe3O4@SiO2 core-shell magnetic microspheres for highly efficient sorption of U(VI). Chem Eng J 235:275-283. https://doi. org/10.1016/j.cej.2013.09.034

4. Prucek R, Hermanek M, Zbořil R (2009) An effect of iron(III) oxides crystallinity on their catalytic efficiency and applicability in phenol degradation-A competition between homogeneous and heterogeneous catalysis. Appl Catal A Gen 366:325-332. https://doi.org/10.1016/j.apcata.2009.07.019

5. Pastrana-Martínez LM, Pereira N, Lima R et al (2015) Degradation of diphenhydramine by photo-Fenton using magnetically recoverable iron oxide nanoparticles as catalyst. Chem Eng J 261:45-52. https://doi.org/10.1016/j.cej.2014.04.117

6. Kharisov Bl, Rasika Dias HV, Kharissova OV et al (2012) Iron-containing nanomaterials: synthesis, properties, and environmental applications. RSC Adv 2:9325. https://doi.org/10.1039/c2ra2 $0812 a$

7. Kim K, Qiu P, Cui M, Khim J (2016) Development and application of Fe3O4-Pd nanospheres as catalyst for electrochemical-heterogeneous Fenton process. Chem Eng J 284:1165-1173. https:// doi.org/10.1016/j.cej.2015.09.035

8. Westerhoff $P$, Alvarez $P$, Li Q et al (2016) Overcoming implementation barriers for nanotechnology in drinking water treatment. Environ Sci Nano 3:1241-1253. https://doi.org/10.1039/C6ENO 0183A

9. Drenkova-Tuhtan A, Schneider M, Franzreb M et al (2017) Pilotscale removal and recovery of dissolved phosphate from secondary wastewater effluents with reusable ZnFeZr adsorbent @ Fe3O4/SiO2 particles with magnetic harvesting. Water Res 109:77-87. https://doi.org/10.1016/j.watres.2016.11.039

10. Wu B, Fang L, Fortner JD et al (2017) Highly efficient and selective phosphate removal from wastewater by magnetically recoverable $\mathrm{La}(\mathrm{OH}) 3 / \mathrm{Fe} 3 \mathrm{O} 4$ nanocomposites. Water Res 126:179-188. https://doi.org/10.1016/j.watres.2017.09.034

11. Farrell JW, Fortner J, Work S et al (2014) Arsenic removal by nanoscale magnetite in Guanajuato, Mexico. Environ Eng Sci 31:1-10. https://doi.org/10.1089/ees.2013.0425

12. Kharisov Bl, Dias HVR, Kharissova OV et al (2012) Iron-containing nanomaterials : synthesis, properties, and environmental applications. RSC Adv 2:9325-9358. https://doi.org/10.1039/c2ra2 0812a

13. Lingamdinne LP, Chang Y, Yang J et al (2017) Biogenic reductive preparation of magnetic inverse spinel iron oxide nanoparticles for the adsorption removal of heavy metals. Chem Eng J 307:74-84. https://doi.org/10.1016/j.cej.2016.08.067

14. Mandel K, Drenkova-Tuhtan A, Hutter F et al (2013) Layered double hydroxide ion exchangers on superparamagnetic microparticles for recovery of phosphate from waste water. J Mater Chem A 1:1840-1848. https://doi.org/10.1039/C2TA00571A

15. Alvarez PJJ, Chan CK, Elimelech M et al (2018) Emerging opportunities for nanotechnology to enhance water security. Nat Nanotechnol 13:634-641

16. Hodges BC, Cates EL, Kim J-H (2018) Challenges and prospects of advanced oxidation water treatment processes using catalytic nanomaterials. Nat Nanotechnol 13:642-650

17. Garrido-Ramírez EG, Theng BKG, Mora ML (2010) Clays and oxide minerals as catalysts and nanocatalysts in Fenton-like reactions-A review. Appl Clay Sci 47:182-192. https://doi. org/10.1016/j.clay.2009.11.044

18. Jiang W, Chen X, Niu Y, Pan B (2012) Spherical polystyrene-supported nano-Fe304of high capacity and low-field separation for arsenate removal from water. J Hazard Mater 243:319-325. https://doi.org/10.1016/j.jhazmat.2012.10.036

19. Zhao X, Shi Y, Wang T et al (2008) Preparation of silica-magnetite nanoparticle mixed hemimicelle sorbents for extraction of several typical phenolic compounds from environmental water samples. J Chromatogr A 1188:140-147. https://doi. org/10.1016/j.chroma.2008.02.069

20. Zhang F, Braun GB, Pallaoro A et al (2012) Mesoporous multifunctional upconversion luminescent and magnetic "nanorattle" materials for targeted chemotherapy. Nano Lett 12:61-67. https://doi.org/10.1021/nl202949y

21. Wu W, He Q, Jiang C (2008) Magnetic iron oxide nanoparticles: Synthesis and surface functionalization strategies. Nanoscale Res Lett 3:397-415. https://doi.org/10.1007/s1167 1-008-9174-9

22. Álvarez PM, Jaramillo J, López-Piñero F, Plucinski PK (2010) Preparation and characterization of magnetic $\mathrm{TiO}_{2}$ nanoparticles and their utilization for the degradation of emerging pollutants in water. Appl Catal B Environ 100:338-345. https://doi. org/10.1016/j.apcatb.2010.08.010

23. Issa B, Obaidat IM, Albiss BA, Haik Y (2013) Magnetic nanoparticles: Surface effects and properties related to biomedicine applications. Int J Mol Sci 14:21266-21305. https://doi.org/10.3390/ ijms 141121266

24. Andreu JS, Camacho J, Faraudo J et al (2011) Simple analytical model for the magnetophoretic separation of superparamagnetic dispersions in a uniform magnetic gradient. Phys Rev E Stat Nonlinear Soft Matter Phys 84:1-8. https://doi.org/10.1103/ PhysRevE.84.021402

25. Hütten A, Sudfeld D, Ennen I et al (2004) New magnetic nanoparticles for biotechnology. J Biotechnol 112:47-63. https://doi. org/10.1016/j.jbiotec.2004.04.019

26. Yavuz CT, Mayo JT, Yu WW et al (2006) Low-field magnetic separation of monodisperse $\mathrm{Fe}_{3} \mathrm{O}_{4}$ nanocrystals. Science 80(314):964-967. https://doi.org/10.1126/science.1131475

27. Ambashta RD, Sillanpää M (2010) Water purification using magnetic assistance: a review. J Hazard Mater 180:38-49. https://doi. org/10.1016/j.jhazmat.2010.04.105

28. Gómez-Pastora J, Bringas E, Ortiz I (2014) Recent progress and future challenges on the use of high performance magnetic nano-adsorbents in environmental applications. Chem Eng J 256:187-204. https://doi.org/10.1016/j.cej.2014.06.119

29. Kolhatkar AG, Jamison AC, Litvinov D, Willson RC (2013) Tuning the magnetic properties of nanoparticles. Chemlnform 45:51

30. Cullity BD, Graham CD (2009) Introduction to magnetic materials. John Wiley \& Sons, New Jersey

31. Girginova PI, Daniel-da-silva AL, Lopes CB et al (2010) Journal of Colloid and Interface Science Silica coated magnetite particles for magnetic removal of $\mathrm{Hg} 2+$ from water. J Colloid Interface Sci 345:234-240. https://doi.org/10.1016/j.jcis.2010.01.087

32. Jack DH, Jack KH (1973) Invited review: carbides and nitrides in steel. Mater Sci Eng 11:1-27. https://doi.org/10.1016/00255416(73)90055-4

33. Hu Y, Jensen JO, Zhang W et al (2014) Hollow spheres of iron carbide nanoparticles encased in graphitic layers as oxygen reduction catalysts. Angew Chemie Int Ed 53:3675-3679. https ://doi.org/10.1002/anie.201400358

34. Herrmann IK, Grass RN, Mazunin D, Stark WJ (2009) Synthesis and covalent surface functionalization of nonoxidic iron coreshell nanomagnets. Chem Mater 21:3275-3281. https://doi. org/10.1021/cm900785u

35. Cohn EM, Hofer BLJ, Cohn EM (1959) Saturation magnetizations of iron carbides1. J Am Chem Soc 81:1576-1582. https://doi. org/10.1021/ja01516a016

36. Brame J, Li Q, Alvarez PJJ (2011) Nanotechnology- enabled water treatment and reuse : emerging opportunities and challenges 
for developing countries. Trends Food Sci Technol 22:618-624. https://doi.org/10.1016/j.tifs.2011.01.004

37. Lingamdinne LP, Koduru JR, Choi $Y$ et al (2016) Studies on removal of $\mathrm{Pb}$ ( II ) and $\mathrm{Cr}$ ( III ) using graphene oxide based inverse spinel nickel ferrite nano-composite as sorbent. Hydrometallurgy 165:64-72. https://doi.org/10.1016/j.hydro met.2015.11.005

38. Lingamdinne LP, Choi Y, Kim I et al (2016) Porous graphene oxide based inverse spinel nickel ferrite nanocomposites for the enhanced adsorption removal of arsenic t. RSC Adv 6:7377673789. https://doi.org/10.1039/c6ra10134h

39. Lingamdinne LP, Koduru JR, Karri RR (2019) A comprehensive review of applications of magnetic graphene oxide based nanocomposites for sustainable water purification. J Environ Manag 231:622-634. https://doi.org/10.1016/j.jenvman.2018.10.063

40. Koduru JR, Karri RR, Mubarak NM (2019) Smart materials magnetic graphene oxide-based nanocomposites for sustainable water purification. In: Mishra RK, Asiri AM (eds) Sustainable polymer composites and nanocomposites. Springer, Cham, pp 759-781

41. Ma J, Zhu Z, Chen B et al (2013) One-pot, large-scale synthesis of magnetic activated carbon nanotubes and their applications for arsenic removal. J Mater Chem A 1:4662-4666. https://doi. org/10.1039/c3ta10329c

42. Lingamdinne LP, Choi Y, Kim I et al (2017) Preparation and characterization of porous reduced graphene oxide based inverse spinel nickel ferrite nanocomposite for adsorption removal of radionuclides. J Hazard Mater 326:145-156. https://doi. org/10.1016/j.jhazmat.2016.12.035

43. Lingamdinne LP, Koduru JR, Chang Y, Karri RR (2018) Process optimization and adsorption modeling of $\mathrm{Pb}$ ( II ) on nickel ferrite-reduced graphene oxide nano-composite. J Mol Liq 250:202-211. https://doi.org/10.1016/j.molliq.2017.11.174

44. Lingamdinne LP, Reddy J, Chang Y et al (2019) Facile synthesis of flowered mesoporous graphene oxide-lanthanum fluoride nanocomposite for adsorptive removal of arsenic. J Mol Liq 279:32-42. https://doi.org/10.1016/j.molliq.2019.01.103

45. Chen B, Zhu Z, Ma J et al (2014) Journal of Colloid and Interface Science One-pot, solid-phase synthesis of magnetic multiwalled carbon nanotube/iron oxide composites and their application in arsenic removal. J Colloid Interface Sci 434:9-17. https://doi. org/10.1016/j.jcis.2014.07.046

46. Lingamdinne LP, Choi J, Choi Y et al (2020) Process modeling and optimization of an iron oxide immobilized graphene oxide gadolinium nanocomposite for arsenic adsorption. J Mol Liq 299:112261. https://doi.org/10.1016/j.molliq.2019.112261

47. Wu Z, Li W, Webley PA, Zhao D (2012) General and controllable synthesis of novel mesoporous magnetic iron oxide @ carbon encapsulates for efficient arsenic removal. Adv Mater 24:485491. https://doi.org/10.1002/adma.201103789

48. Mahmoodi NM, Abdi J, Bastani D (2014) Direct dyes removal using modified magnetic ferrite nanoparticle. J Environ Heal Sci Eng 12:96. https://doi.org/10.1186/2052-336X-12-96

49. Zhou Z, Liu Y, Liu S et al (2017) Sorption performance and mechanisms of arsenic (V) removal by magnetic gelatin-modified biochar. Chem Eng J 314:223-231. https://doi.org/10.1016/j. cej.2016.12.113

50. Fawell J, Nieuwenhuijsen MJ (2003) Contaminants in drinking water. Br Med Bull 68:199-208. https://doi.org/10.1093/bmb/ Idg027

51. Sharma SK, Sanghi R (2013) Wastewater reuse and management. Springer, Dordrecht

52. Westerhoff $P$, Benn T, Chen AS, et al (2008) Assessing arsenic removal by metal (hydr) oxide adsorptive media using rapid small scale column tests.
53. Zheng $Y$ (2017) Lessons learned from arsenic mitigation among private well households. Curr Environ Heal reports 4:373-382

54. Deng Y, Qi D, Deng C et al (2008) Superparamagnetic highmagnetization microspheres with an $\mathrm{Fe}_{3} \mathrm{O}_{4} @ \mathrm{SiO}_{2}$ core and perpendicularly aligned mesoporous $\mathrm{SiO}_{2}$ shell for removal of microcystins. J Am Chem Soc 130:28-29

55. Lounsbury AW, Yamani JS, Johnston CP et al (2016) The role of counter ions in nano-hematite synthesis: implications for surface area and selenium adsorption capacity. J Hazard Mater 310:117-124. https://doi.org/10.1016/j.jhazmat.2016.01.078

56. Girolami GS (2016) X-ray crystallography. University Science Books, Mill Valley, California

57. Ersan G, Apul OG, Perreault F, Karan T (2017) Adsorption of organic contaminants by graphene nanosheets : a review. Water Res. https://doi.org/10.1016/j.watres.2017.08.010

58. National Science Foundation NSF/ANSI 53 Standards for Water Treatment Systems. https://www.nsf.org/consumer-resources/ water-quality/water-filters-testing-treatment/standards-water -treatment-systems. Accessed 20 Jul 2017

59. Sidhu PS (1981) Dissolution of iron oxides and oxyhydroxides in hydrochloric and perchloric acids. Clays Clay Miner 29:269-276. https://doi.org/10.1346/CCMN.1981.0290404

60. American Public Health Association, American Water Works Association, Water Environment Federation (1999) 3500-Fe B. Phenanthroline Method. In: Standard Methods for the Examination of Water and Wastewater Standard

61. Sandoval R, Cooper AM, Aymar K et al (2011) Removal of arsenic and methylene blue from water by granular activated carbon media impregnated with zirconium dioxide nanoparticles. J Hazard Mater 193:296-303. https://doi.org/10.1016/j.jhazm at.2011.07.061

62. Oberteuffer J (1973) High gradient magnetic separation. Magn IEEE Trans 9:303-306. https://doi.org/10.1109/TMAG.1973.10676 73

63. Moeser GD, Roach KA, Green WH et al (2004) High-gradient magnetic separation of coated magnetic nanoparticles. AIChE J 50:2835-2848. https://doi.org/10.1002/aic.10270

64. Oberteuffer J (1974) Magnetic separation: a review of principles, devices, and applications. Magn IEEE Trans 10:223-238. https:// doi.org/10.1109/TMAG.1974.1058315

65. Larumbe S, Gómez-Polo C, Pérez-Landazábal Jl, Pastor JM (2012) Effect of a $\mathrm{SiO}_{2}$ coating on the magnetic properties of $\mathrm{Fe}_{3} \mathrm{O}_{4}$ nanoparticles. J Phys Condens Matter 24:266007. https://doi. org/10.1088/0953-8984/24/26/266007

66. El Mendili Y, Bardeau J-F, Randrianantoandro N et al (2012) Insights into the mechanism related to the phase transition from $\mathrm{Y}-\mathrm{Fe}_{2} \mathrm{O}_{3}$ to $\mathrm{a}-\mathrm{Fe}_{2} \mathrm{O}_{3}$ nanoparticles induced by thermal treatment and laser irradiation. J Phys Chem C 116:23785-23792. https://doi.org/10.1021/.jp308418x

67. Mahmoudi M, Sant S, Wang B et al (2011) Superparamagnetic iron oxide nanoparticles (SPIONs): development, surface modification and applications in chemotherapy. Adv Drug Deliv Rev 63:24-46. https://doi.org/10.1016/j.addr.2010.05.006

68. Qu X, Alvarez PJJ, Li Q (2013) Applications of nanotechnology in water and wastewater treatment. Water Res 47:3931-3946. https://doi.org/10.1016/j.watres.2012.09.058

69. Tang T, Liu F, Liu Y et al (2014) Identifying the magnetic properties of graphene oxide. Appl Phys Lett 123104:27-32. https:// doi.org/10.1063/1.4869827

70. Veligatla M, Katakam S, Das S et al (2015) Effect of iron on the enhancement of magnetic properties for cobalt-based soft magnetic metallic glasses. Metall Mater Trans A 46:1019-1023. https://doi.org/10.1007/s11661-014-2714-2

71. Cheng Y, Tan R, Wang W (2010) Controllable synthesis and magnetic properties of $\mathrm{Fe}_{3} \mathrm{O}_{4}$ and $\mathrm{Fe}_{3} \mathrm{O}_{4} @ \mathrm{SiO}_{2}$ microspheres. 
J Mater Sci 45:5347-5352. https://doi.org/10.1007/s1085 3-010-4583-4

72. Cornell RM, Posner AM, Quirk JP (1976) Kinetics and mechanisms of the acid dissolution of goethite (a-FeOOH). J Inorg Nucl Chem 38:563-567. https://doi.org/10.1016/0022-1902(76)80305-3

73. Gawande MB, Monga Y, Zboril R, Sharma RK (2015) Silicadecorated magnetic nanocomposites for catalytic applications. Coord Chem Rev 288:118-143. https://doi.org/10.1016/j. ccr.2015.01.001

74. Ungureanu G, Santo S, Boaventura R, Botelho C (2015) Arsenic and antimony in water and wasterwater: overview of removal techniques with special reference to latest advances in adsorption. J Environ Manag 151:326-346

75. Mondal MK, Garg R (2017) A comprehensive review on removal of arsenic using activated carbon prepared from easily available waste materials. Environ Sci Pollut Res 24:13295-13306

76. Mohan D, Pittman CU (2007) Arsenic removal from water/ wastewater using adsorbents-A critical review. J Hazard Mater 142:1-53. https://doi.org/10.1016/j.jhazmat.2007.01.006
77. Gutierrez-muñiz OE, García-rosales G, Ordoñez-regil E et al (2013) Synthesis, characterization and adsorptive properties of carbon with iron nanoparticles and iron carbide for the removal of As (V) from water. J Environ Manag 114:1-7. https://doi. org/10.1016/j.jenvman.2012.09.027

78. Clark CA, Heck KN, Powell CD, Wong MS (2019) Highly defective UiO-66 materials for the adsorptive removal of Perfluorooctanesulfonate. ACS Sustain Chem Eng 7:6619-6628. https://doi. org/10.1021/acssuschemeng.8b05572

79. Yu J, Chen F, Gao W et al (2017) Iron carbide nanoparticles : an innovative nanoplatform for biomedical applications. Nanoscale Horizons 2:81-88. https://doi.org/10.1039/C6NH00173D

Publisher's Note Springer Nature remains neutral with regard to jurisdictional claims in published maps and institutional affiliations. 